\title{
PENGARUH PENGAWASAN FUNGSIONAL, PENGELOLAAN KEUANGAN, DAN KEJELASAN SASARAN ANGGARAN TERHADAP AKUNTABILITAS KINERJA INSPEKTORAT KOTA MALANG
}

\author{
Maria Novriana Mina \\ Email: minanovriana30@gmail.com \\ Anwar Made \\ Rita Indah Mustikowati \\ Jurusan Akuntansi, Fakultas Ekonomika Dan Bisnis, Universitas Kanjuruhan Malang
}

\begin{abstract}
ABSTRAK
Penelitian ini dilakukan untuk menguji dan mengetahui pengaruh pengawsan fungsional, pengelolaan keuangan, dan kejelasan sasaran anggaran terhadap akuntabilitas kinerja Inspektorat Kota Malang. Jenis penelitian ini adalah penelitian kuantitatif, sumber data yang digunakan adalah data primer, teknik pengambilan sampel menggunakan metode total sampling, selanjutnya dianalisis dengan model regresi linear berganda. Hasil penelitian menunjukan bahwa pengawsan fungsional, pengelolaan keuangan dan kejelasan sasaran anggaran secara simultan berpengaruh terhadap akuntabilitas kinerja, secara parsial pengawasan fungsional berpengaruh terhadap akuntabilitas kinerja, pengelolaan keuangan berpengaruh terhadap akuntabilitas kinerja dan kejelasan sasaran anggaran berpengaruh terhadap akuntabilitas kinerja.
\end{abstract}

Kata kunci: pengawasan fungsional, pengelolaan keuangan, kejelasan sasaran anggaran, akuntabilitas kinerja.

\begin{abstract}
This research was conducted to examine and determine the effect of functional supervision, financial management, and clarity of budget targets on the performance accountability of the Inspectorate of Malang. This type of research is quantitative research, the source of the data used is primary data, sampling techniques using total sampling method, then analyzed with multiple linear regression models. The results showed that functional oversight, financial management and clarity of budget objectives simultaneously affect performance accountability, functional supervision partially influences performance accountability, financial management influences performance accountability and clarity of budget targets affects performance accountability.
\end{abstract}

Keywords: functional supervision, financial management, clear budgetary objectives, performance accountability. 


\section{PENDAHULUAN}

Perkembangan akuntansi sektor publik, khususnya di Indonesia semakin pesat dengan adanya era reformasi dalam pelaksanaan kebijakan pemerintah otonomi daerah dan desentralisasi fiskal yang menitikberatkan pada pemerintah daerah. Selain itu, maraknya globalisasi yang menuntut daya saing disetiap negara juga menuntut daya saing disetiap pemerintah daerahnya. Daya saing pemerintah daerah ini diharapkan akan tercapai melalui peningkatan kemandirian pemerintah daerah yang dapat diraih melalui adanya otonomi daerah.

Fenomena yang terjadi ditahun lalu cukup banyak menyedot perhatian masyarakat Malang, diketahui bahwa postur Anggaran Pendapatan Dan Belanja Daerah (APBD) kota Malang tahun 2018 masih didominasi kebutuhan belanja tidak langsung. Belanja tidak langsung menyedot anggaran sekitar Rp 2,1 triliun atau 56,76\% yang terbagi dalam enam pos dari total APBD sebesar Rp 3,7 triliun. Angka belanja tidak langsung tersebut membuat beberapa kalangan mengaitkannya dengan kinerja Organisasi Perangkat Daerah (OPD) kota Malang, khususnya di alokasi belanja pegawai ada penilaian besaran belanja pegawai tidak selaras dengan capaian yang diharapkan, hal ini terjadi masih lebih dominan belanja tidak langsung, untuk belanja langsung atau program bagi masyarakat angkanya turun dari $\mathrm{Rp} 1,143$ triliun menjadi $\mathrm{Rp} 1,064$ triliun. Belanja langsung masih ada juga jatah gaji atau tunjangan-tunjangan dari luar pokok gaji pegawai artinya tidak murni untuk masyarakat. Penggunaan sisah lebih pengguna anggaran (Slipa) sebagai penambal kebutuhan belanja dinilai merupakan imbas dari buruknya perencanaan program (Malang Times, 2 November 2018).

Akuntabilitas yang baik merupakan pertanggungjawaban yang dilakukan dengan review, evaluasi, pemantauan, dan kegiatan pengawasan lain terhadap penyelenggaraan tugas dan fungsi organisasi dalam rangka memberikan keyakinan yang memadai bahwa kegiatan telah dilaksanakan sesuai dengan tolok ukur yang telah ditetapkan secara efektif dan efisien untuk kepentingan pimpinan dalam mewujudkan tata kepemerintahan yang baik (Peraturan Wali Kota Malang nomor 8 tahun 2016 tentang Piagam Pelaksanan Pengawasan Inspektorat Kota Malang).

Pengawasan fungsional sangat berperan dan memiliki kaitan langsung dengan akuntabilitas dalam tata kelola pemerintah yang memberi landasan, pedoman dan batasan kewenangan, tanggung jawab dan lingkup pengawasan bagi aparat Inspektorat untuk menjamin terlaksananya pelaksanaan tugas pengawasan keuangan pemerintah maupun pembangunan pemerintah, agar terwujudnya aparatur yang bersih dan berwibawa ( Halim, 2010). Maka hal tersebut, dapat menyimpulkan bahwa, Tujuan utama dari pengawasan fungsional untuk pemerintah yang akuntabilitas yaitu mengatur aparat pemerintah yang bersih dari Korupsi,Kolusi dan Nepotisme sehingga sebagai upaya good governance.

Pengelolaan pemerintah daerah yang akuntabilitas, juga tidak terlepas dari anggaran, Salah satu karakteristik anggaran adalah kejelasan sasaran anggaran, Pada konteks pemerintah daerah, sasaran anggaran tercakup dalam Rencana Strategik Daerah (Renstrada) dan Program Pembangunan Daerah (Propeda). Dalam keberhasilan kejelasan sasaran anggaran maka diharapkan akan tercapainya tugas suatu organisasi sehingga akan mewujudkan akuntabilitas publik. Akuntabilitas publik dapat terwujud dengan adanya pelaksanaan anggaran yang efektif, efesien dan transparan.

Dari uraian tersebut peneliti dapat menulis rumusan masalah: 1. Bagaimana pengaruh pengawasan fungsional, pegelolaan keuangan, kejelasan sasaran anggaran terhadap akunbtabilitas kinerja Inspektorat Kota Malang? 2. Bagaimana pengaruh pengawasan fungsional terhadap akuntabilitas kinerja Inspektorat Kota Malang? 3. Bagaimana pengaruh pengelolaan keuangan terhadap akuntabilitas kinerja Inspektorat 
Kota Malang? 4. Bagaimana pengaruh kejelasan sasaran anggaran terhadap akuntabilitas kinerja Inspektorat Kota Malang?

\section{TINJAUAN PUSTAKA}

\section{Akuntansi Sektor Publik}

Menurut Halim (2010) good governace merupakan sesuatu penyelenggaraan manajemen pembangunan yang bertanggung jawab dengan sejalan prinsip demokrasi, penghindaran salah alokasi dana investasi,dan pencegahan korupsi baik secara politik maupun secara administratif. Good governance mendasarkan suatu konsep yang mengacu kepada proses pencapaian keputusan dan pelaksannya dapat dipertanggungjawabkan secara bersama. Menurut Mardiasmo (2009) good governace merupakan suatu konsep pendekatan yang berorentasi kepada pembangunan sektor publik oleh pemerintah yang baik.

\section{Akuntabilitas}

Akuntabilitas merupakan pemberian informasi dan pengungkapan (disclosure) atas aktivitas dan kinerja finansial pemerintah daerah kepada pihak-pihak yang berkepentingan dengan principal (Mardiasmo: 2004).

Akuntabilitas pablik sebagai bentuk kewajiban mempertanggung jawabkan keberhasilan dan kegagalan dalam segala aktifitas yang menjadi tanggung jawab kepada pihak yang memberi amanah.

Akuntabilitas kinerja akuntansi pemerintah adalah perwujudan kewajiban suatu istansi pemerintah untuk mempertanggungjawabkan keberhasilan atau kegagalan pelaksanan misi organiasasi dalam maencapai tujuan dan sasaran yang telah di tentukan. Pengukuran akuntabilitas dapat di ukur melalui alat pertanggungjawaban secara periodik yaitu proses, program, kebijakan, hukum dan kejujuran.

\section{Pengawasan fungsional}

Pengawasan fungsional adalah pengawasan yang dilakukan oleh lembaga yang tugas pokok dan fungsinya adalah melakukan pengawasan. Menurut Baldric (2015) pengawasan fungsional adalah pengawasan yang dilakukan oleh aparat pengawasan fungsional APBD yang meliputi BPKP, BPK.

Pengawasan fungsional terdiri atas kegiatan pemeriksaan, pengujian, penilaian, monitoring, serta efaluasi yang diarahkan untuk menjegah timbulnya berbagai macam bentuk penyimpangan dan pelaksanaan kegiatan pemerintahan sudah sesuai dengan rencana dan praturan perundang- undang yang berlaku.

\section{Kejelasan sasaran anggaran}

Kejelasan sasaran anggaran menggambarkan luasnys pertimbangan kebutuhan pencapaian dimasa sekarang atau masa yang akan datang. Sasaran anggaran adalah hasil yang dicapai atau target yang diharapkan dari suatu program atau kegiatan (Peraturan Mentri dalam Negeri Nomor 13 tahun 2006 tetantan Pengelolaan Keuanga Daerah).

Menurut Irine (2015) Anggaran adalah suatu rencana yang dinyatakan secara kuantitatif dalam satuan uang yang berjangka waktu tertentu, biasanya satu tahun. Salah satu karakteristik anggaran adalah kejelasan sasaran anggaran, dengan adanya sasaran anggaran yang jelas maka, akan memudahkan individu untuk menyusun target- target anggaran yang sesuai dengan sasaran yang ingin dicapai organisasi. Pada konteks Pemerintah Daerah, kejelasan sasaran anggaran berimplikasi pada aparat untuk menyusun anggaran sesuai dengan sasaran yang ingin dicapai instansi pemerintah. Aparat akan memiliki informasi yang cukup untuk memprediksi masa depan secara tepat. 
Pengelolaan keuangan daerah

Pengelolaan keuangan merupakan jumlah alokasi anggaran serta jumlah partisipasi dalam perencanaan, pelaksanaan, dan pengawasan keuanga daerah yang dilakukan dalam kurun waktu tertentu dan mempunyai pengelolaan keuangan yang efektif dan efesien sehingga menciptakan akuntabilitas yang tinggi

Pengelolaan keuangan yang diatur dalam peraturan menteri yang meliputi kekuasaan pengelolaan keuangan daerah, azas umum dan struktur APBD, penyusunan rancangan $\mathrm{APBD}$, penetapan $\mathrm{APBD}$, penyusunan dan penetapan $\mathrm{APBD}$ bagi daerah yang belum memiliki DPRD, pelaksanaan APBD, pembinaan dan pengawasan pengelolaan keuangan daerah, kerugian daerah dan pengelolaan keuangan BLUD. Menurut Permendagri nomor 59 tahun 2007 tentang pedoman pengelolaan keuangan daerah, bahwa pengelolaan keuangan daerah adalah keseluruhan kegiatan yang meliputi perencanaan, pelaksanaan, penatausahaan, pelaporan, pertanggungjawaban dan pengawasan keuangan daerah.

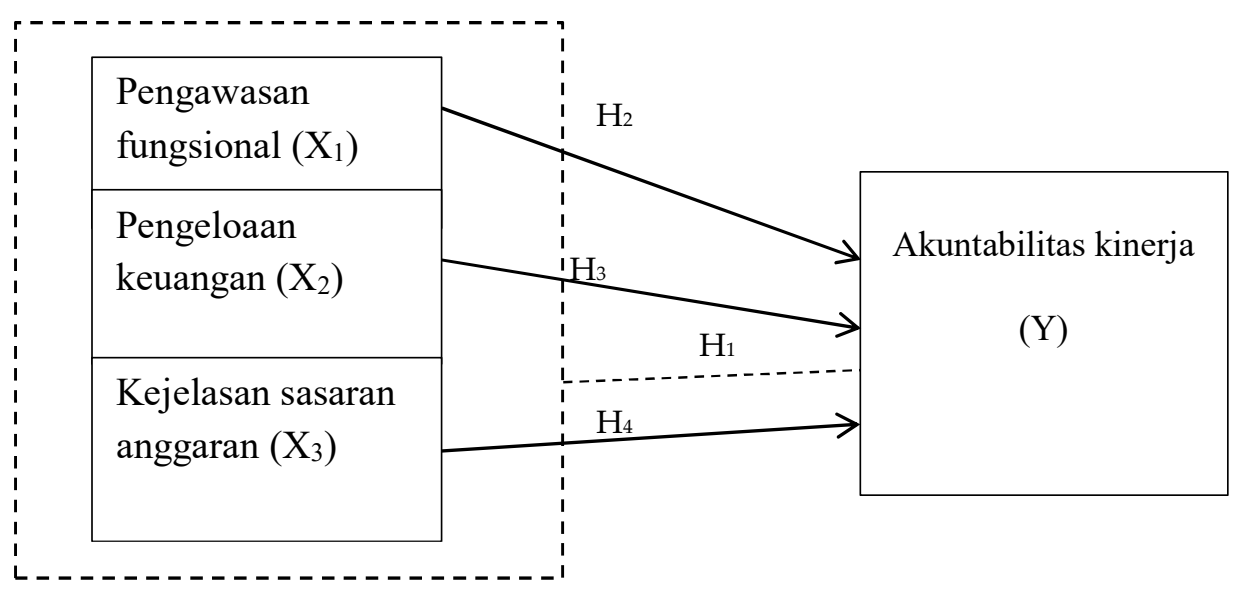

\section{Gambar 2.2 Kerangka Konsep}

\section{HIPOTESIS PENELITIAN}

1. Pengawasan fungsional, pengelolaan keuangan dan kejelasan sasaran anggaran terhadap akuntabilitas kinerja

2. Pengawsan fungsional berpengaruh terhadap akuntabilitas kinerja

3. Pengelolaan keuangan berpengaruh terhadap akuntabilitas kinerja

4. Kejelasan sasaran anggaran berpengaruh terhdap akuntabilitas kinerja

\section{METODE}

Jenis penelitian ini merupakan penelitian kuantitatif, . Sumber data yang digunakan yaitu data primer, yaitu pengambilan data secara langsung dengan cara penyampaian kuesioner kepada responden. Populasi yang digunakan dalam penelitian ini adalah adalah seluruh aparatur di inspektorat kota Malang yang berjumlah 50 orang. Teknik pengambilan sampel ini menggunakan metode total sampling, menurut Ari Kunto (2012) jika jumlah populasinya kurang dari 100 orang maka jumlah sampelnya diambil secara keseluruhan, tetapi jika jumlah populasinya lebih besar dari 100 orang, maka bisa diambil $10-15 \%$ dari jumlah populasinya. Berdasarkan penelitian ini karena jumlah populasinya kurang dari 100 responden, maka peneliti mengambil semua jumlah 
populasi yang ada di Inspektorat Kota Malang. Sumber data yang digunakan dalam penelitin ini adalah data primer, data primer merupakan data yang yang pertama kali dikumpulkan, diperoleh atau dicatat oleh peneliti dari sumbernya langsung (Sarwoko, 2018). Sumber data dalam penelitian ini adalah seluruh aparat Inspektorat Kota Malang. Instrumen yang digunakan dalam penelitian ini adalah kuisioner yang diambil berdasarkan teori dan tinjaun dari peneliti terdahulu, data diperoleh dengan mengirim kuisioner secara langsung kepada setiap responden yaitu seluruh aparat Inspektorat Kota Malang, Masing-masing variabel diukur dengan skal likert yang mengatakan setuju atau tidak setuju, terhadap pernyataan yang akan diajukan dengan skor 1-5.

\section{HASIL DAN PEMBAHASAN}

\section{Analisis Hasil Penelitian}

Uji asumsi klasik merupakan tahap awal yang digunakan sebelum analisis regresi berganda bertujuan untuk mengetahui model regresi benar-benar menunjukan hubungan signifikan dan representative.

\section{Hasil uji multikolinieritas}

Pengujian multikolinieritas dilihat dari besaran VIF ( Variance Inflation Factor) dan tolerance. Jika VIF > 10 maka tidak terjadi gejala multikolonieritas.

Tabel 4.10

Hasil uji multikolineritas

\begin{tabular}{|c|c|c|c|c|c|c|c|}
\hline \multirow[b]{2}{*}{ Model } & \multicolumn{2}{|c|}{$\begin{array}{c}\text { Unstandardized } \\
\text { Coefficients }\end{array}$} & \multirow{2}{*}{$\begin{array}{c}\begin{array}{c}\text { Standardiz } \\
\text { ed } \\
\text { Coefficient } \\
\mathrm{s}\end{array} \\
\text { Beta }\end{array}$} & \multirow[b]{2}{*}{$\mathrm{t}$} & \multirow[b]{2}{*}{ Sig. } & \multicolumn{2}{|c|}{$\begin{array}{c}\text { Collinearity } \\
\text { Statistics }\end{array}$} \\
\hline & B & $\begin{array}{l}\text { Std. } \\
\text { Error }\end{array}$ & & & & $\begin{array}{c}\text { Toleranc } \\
\mathrm{e}\end{array}$ & VIF \\
\hline (Constant) & 23,255 & 5,996 & & 3,879 &, 000 & & \\
\hline $\begin{array}{l}\text { PENGAWASA } \\
\mathrm{N} \\
\text { FUNGSIONAL }\end{array}$ & ,270 & ,094 & ,312 & 2,872 & ,006 & 808 & 1,237 \\
\hline $\begin{array}{l}\text { PENGELOLAA } \\
\text { N KEUANGAN }\end{array}$ & 289 & 090 & ,374 & 3,198 & ,003 & 698 & 1,432 \\
\hline $\begin{array}{l}\text { KEJELASAN } \\
\text { SASARAN }\end{array}$ & 318 & 101 & 334 & 3.155 & 003 & 851 & 1.176 \\
\hline ANGGARAN & & & & & & & \\
\hline
\end{tabular}

Sumber : data primer diolah 2020

Tabel 4.10 menunjukan bahwa nilai VIF pada kolom Collinearity Statistic, untuk variabel pengawasan fungsional niali VIF sebesar 1,237, variabel pengelolaan keuangan nilai VIF sebesar 1,432, variabel kejelasan sasaran anggaran nilai VIF sebesar 1,176 karena setiap variabel lebih kecil dari 10 maka tidak menunjukan adanya gejala multikoloneritas.

\section{Hasil Uji Autokorelasi}

Untuk mendeteksi terhadap gejala autokorelasi dilakukan dengan pengujian Durbin Watson (d). Hasil Durbin Watson (d) dibandingkan dengan nilai d tabel pada $\alpha=$ 0,05 , tabel $\mathrm{d}$ memiliki dua nilai yaitu nilai batas atas $\left(\mathrm{d}_{\mathrm{u}}\right)$ dan nilai batas bawah $\left(\mathrm{d}_{\mathrm{t}}\right)$ untuk berbagai nilai $\mathrm{n}$ dan $\mathrm{k}$. 
Tabel 4.11

Hasil Uji Autokorelasi

Model Summary ${ }^{b}$

\begin{tabular}{|l|c|r|r|r|r|}
\hline $\begin{array}{l}\text { Mode } \\
1\end{array}$ & $\mathrm{R}$ & R Square & \multicolumn{1}{|c|}{$\begin{array}{c}\text { Adjusted R } \\
\text { Square }\end{array}$} & $\begin{array}{l}\text { Std. Error of } \\
\text { the Estimate }\end{array}$ & $\begin{array}{l}\text { Durbin- } \\
\text { Watson }\end{array}$ \\
\hline 1 &, $749 \mathrm{a}$ &, 562 &, 533 & 5,460 & 1,938 \\
\hline
\end{tabular}

Sumber: data primer diolah 2020

Dari tabel 4.11 dilihat nilai durbin watson 1,938, pengujian autokorelasi dilakukan dengan cara membandingkan nilai durbin watson dengan nilai tabel $\left(\mathrm{d}_{\mathrm{u}} \mathrm{dan} \mathrm{d}_{\mathrm{t}}\right)$ pada taraf $\alpha$ dan $n=50$. Nilai $\mathrm{d}_{\mathrm{u}}=1,27$ dan nilai $\mathrm{d}_{\mathrm{L}}=1,65$ karena nilai durbin watson lebih besar dari nilai $d_{u}$ dan lebih kecil dari 4-du maka dapat dinyatakan model regresi bebas gejala autokorelasi.

\section{Hasil uji heteroskedastisitas}

Model regresi linear mengasumsikan bahwa varian residual besifat konstanta atau sama, model regresi yang baik adalah tidak terjadi heteroskedastisitas. Untuk mengetahui ada tidaknya heteroskedastisitas dilakukan dengan metode scatterplot, jika grafik plot menunjukan tidak beraturan maka dinyatakan tidak terjadi heteroskedastisitas. Hasil uji heteroskedastisitas disajikan pada gambar:

Scatterplot

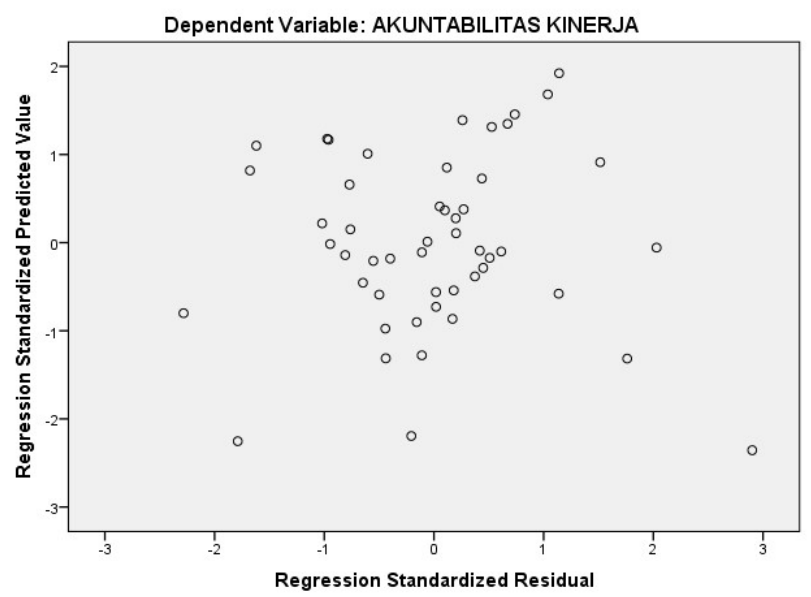

Gambar 4.1

Hasil uji heteroskedastisitas

Gambar 4.1 menunjukan bahwa gambar scaterplot tidak beraturan dan membentuk suatu pola atau gambar tertentu. Hal ini menunjukan bahwa ketidak samaan variance dari residual satu pengamatan ke pengamatan yang lain.

\section{Hasil uji normalitas}

Uji normalitas bertujuan untuk mengetahui apakah dalam model regresi variabel pengganggu mempunyai distribusi normal ataukah tidak. Model regresi yang baik adalah memiliki distribusi data normal atau mendekati normal. Hasil uji normalitas dapat dilihat pada tabel berikut: 


\section{Hasil uji normalitas}

\begin{tabular}{|ll|r|}
\hline & & \multicolumn{1}{|c|}{ Unstandardized Residual } \\
\hline $\mathrm{N}$ & & 50 \\
Normal Parameters ${ }^{\mathrm{a}, \mathrm{b}}$ & Mean &, 0000000 \\
& Std. Deviation & 5,29014176 \\
Most Extreme Differences & Absolute &, 093 \\
& Positive &, 093 \\
& Negative &,- 066 \\
Test Statistic & &, 093 \\
Asymp. Sig. (2-tailed) & &, $200^{\mathrm{c}, \mathrm{d}}$ \\
\hline
\end{tabular}

Sumber: data primer dioleh 2020

Berdasarkan tabel 4. 12 Menunjukan bahwa nilai signifikan kolmograf smirnov sebesar 0,200 melebihi 0,05 (5\%), hal ini menunjukan bahwa data tersebut berdistribusi normal.

\section{Hasil Uji Hipotesi}

Pengujian hipotesis penelitian yaitu pengawasan fungsional, pengelolaan keuangan, kejelasan sasaran anggaran secara parsial dan simultan berpengaruh terhadap variabel dependent yaitu akuntabilitas.

\section{Hasil uji simultan (f)}

Uji f merupakan yang pada dasarnya menunjukan apakah semu variabel independen yang dimasukan dalam model mempunyai pengaruh secara bersama-sama terhadap variabel dependent. Uji f digunakan untuk menguji signifikan $\mathrm{X}$ terhadap $\mathrm{Y}$, nilai signifikansi ditunjukan dengan lebih kecil dari $\alpha=0,05$. Hasil uji f dapat dilihat pada tabel berikut:

Tabel 4. 1

Hasil uji simultan

\begin{tabular}{|c|c|c|c|c|c|c|}
\hline \multicolumn{2}{|c|}{ Model } & $\begin{array}{l}\text { Sum of } \\
\text { Squares }\end{array}$ & $\mathrm{df}$ & Mean Square & $\mathrm{F}$ & Sig. \\
\hline \multirow[t]{3}{*}{1} & Regression & 1756,326 & 3 & 585,442 & 19,639 &, $000^{\mathrm{b}}$ \\
\hline & Residual & 1371,294 & 46 & 29,811 & & \\
\hline & Total & 3127,620 & 49 & & & \\
\hline
\end{tabular}

Berdasarkan tabel 4.1 terlihat bahwa nilai signifikan uji F sebesar 0,000 lebih kecil alpha 0,05 , jadi hipotesis pertama yang menyatakan bahwa variabel pengawasan fungsional, pengelolaan keuangan, dan kejelasan sasaran anggaran berpengaruh terhadap akuntabilitas kinerja dapat diterima.

2. Hasil uji parsial (t)

a. Hasil uji hipotesis kedua

Uji hipotesis pertama menggunakan uji t memperhatikan tabel 4.13 terlihat bahwa nilai signifikan uji t sebesar 0,006 lebih kecil alpha 0,05, jadi hipotesis kedua yang menyatakan variabel pengawasan fungsional berpengaruh terhadap akuntabilitas kinerja dapat diterima.

b. Hasil uji hipotesis ketiga

Uji hipotesis kedua menggunakan uji $\mathrm{t}$, memperhatikan tabel 4.13 terlihat bahwa nilai signifikan uji t sebesar 0,003 lebih kecil alpha 0,05, jadi hipotesis ketiga yang menyatakan variabel pengelolaan keuangan berpengaruh terhadap akuntabilitas kinerja dapat diterima.

c. Hasil uji hipotesis keempat 
Uji hipotesis keempat menggunakna uji t, memperhatiakan tabel 4.13 terlihat bahwa nilai signifikan uji t sebesar 0,003 lebih kesil alpha 0,05, jadi hipotesis keempat yang menyatakan variabel kejelasan sasaran anggaran berpengaruh terhadap akuntabilitas kinerja dapat diterima.

Tabel 4.2

Hasil uji parsial (t)

\begin{tabular}{|c|c|c|c|c|c|c|c|c|c|}
\hline \multirow{2}{*}{\multicolumn{2}{|c|}{ Model }} & \multicolumn{2}{|c|}{$\begin{array}{c}\text { Unstandardiz } \\
\text { ed } \\
\text { Coefficients }\end{array}$} & \multirow{2}{*}{$\begin{array}{c}\text { Standardize } \\
\mathrm{d} \\
\text { Coefficients }\end{array}$} & \multirow[b]{2}{*}{$\mathrm{T}$} & \multirow[b]{2}{*}{ Sig. } & \multicolumn{3}{|c|}{ Correlations } \\
\hline & & B & $\begin{array}{l}\text { Std. } \\
\text { Error }\end{array}$ & & & & $\begin{array}{l}\text { Zero- } \\
\text { order }\end{array}$ & $\begin{array}{c}\text { Parti } \\
\text { al }\end{array}$ & Part \\
\hline & (Constant) & 23,255 & 5,996 & & 3,879 & ,000 & & & \\
\hline & $\begin{array}{l}\text { PENGAWASA } \\
\mathrm{N}\end{array}$ & 270 & ,094 & 312 & 2,872 & ,006 & 503 & 390 & 280 \\
\hline & FUNGSIONAL & & & & & & & & \\
\hline & PENGELOLA & & & & & & & & \\
\hline & AN & ,289 & ,090 & ,374 & 3,198 & ,003 & 634 & ,427 & 312 \\
\hline & KEUANGAN & & & & & & & & \\
\hline & KEJELASAN & & & & & & & & \\
\hline & SASARAN & ,318 & 101 & ,334 & 3,155 & ,003 & ,503 & ,422 & ,308 \\
\hline & ANGGARAN & & & & & & & & \\
\hline
\end{tabular}

Sumber: data primer dioleh 2020

\section{Pengaruh Pengawsan Fungsional, Pengelolaan Keuangan, Kejelasan Sasaran Anggaran Terhadap Akuntabilitas Kinerja}

Hasil uji hipotesis pertama menyebutkan bahwa pengawasan fungsional, pengelolaan keuangan dan kejelasan sasaran anggaran berpengaruh terhadap akuntabilitas kinerja yang didukung oleh data dengan kata lain bahwa hipotesis diterima. Hal ini berati bahwa pengawasan fungsional, pengelolaan keuanga dan kejelsan sasaran anggaran terhadap akuntabilitas sebesar 0,562 sedangkan sisanya 0,438 dipengaruh oleh variabel lain yang tidak dibahas dalam penelitian ini.

\section{Pengaruh Pengawsan Fungsional Terhadap Akuntabilitas Kinerja}

Berdasarkan hasil penelitian, hipotesis kedua pengawasan fungsional berkontribusi terhadap akuntabilitas kinerja. Tabel analisis regresi linear berganda menunjukan nilai signifikansi variabel pengawasan fungsional sebesar 0,006 (lebih kecil dari $\alpha=0,05$ ).

\section{Pengaruh Pengelolaan Keuangan Terhadap Akuntabilitas Kinerja}

Berdasarkan hasil penelitian, hipotesis ketiga pengelolaan keuangan berkontribusi terhadap akuntabilitas kinerja. Tabel hasil analisis regresi linear berganda menunjukan nilai signifikan variabel pengelolaan keuangan sebesar 0,003. Hal ini berati semakin tinggi pengelolaan keuangan maka akuntabilitas kinerja yang dihasilkan semakin baik.

\section{Pengaruh Kejelasan Sasaran Anggaran Terhadap Akuntabilitas Kinerja}

Berdasarkan hasil penelitian, hipotesis keempat yang menyebutkan bahwa kejelasan sasaran anggaran berpengaruh terhadap akuntabilitas kinerja berhasil didukung oleh data atau dengan kata lain hipotesis diterima. Tabel analisis regresi linear berganda menunjukan nilai signifikan variabel kejelasan sasaran anggaran sebesar 0,003 (lebih kecil dari $\alpha=0,05)$. Hal ini berati semakin tinggi kejelasan sasaran anggaran, maka akuntabilitas kinerja yang dihasilkan semakin baik. 


\section{Daftar Pustaka}

Arikunto, S. 2010. Prosedur Penelitian Pendekatan Praktik. Jakarta: Bhineka Cipta

Halim, Abdul. 2010. Sistem Akuntansi sektor publik. Yogyakarta: UUP STIM YKPN

Irene. 2015. Pengaruh Kejelasan Sasaran Anggaran, Pengendalian Akuntansi, Sistem Pelaporan Terhadap Akuntabilitas Kinerja di SKPD Merauke. Jurnal disajikan dalam Seminar Multi Disiplin Ilmu Untuk Mewujudkan Poros Maritim dalam Pembangunan Ekonomi, Fakultas Ekonomi dan Bisnis Universitas Stikubank Semarang

MalangTimes 2 novemeber 2018.2,1 Triliun pendapatan daerah kabupaten malang tersedot belanja tidak langsung.

Mardiasmo. 2004. Akuntansi Sektor Publik.Yogyakarta: Andi

Mardiasmo. 2009. Akuntansi Sektor Publik. Yogyakarta: Andi

Peraturan walikota Malang No 8 tahun 2016 tentang Piagam Pelaksanaan Pengawasan Inspektorat Kota Malang. (Online), (hukum.malangkota.go.id), diakses 21 oktober 2019

Sarwoko, Endi. 2018. Buku Ajar Metodelogi Penelitian

Siregar, Baldric. 2015. Akuntansi Keuangan Daerah Berbasis Akrual. Yogyakarta: UPP STIM YKPN 